\title{
Comparison of SYBR Green I and SYBR Gold stains for enumerating bacteria and viruses by epifluorescence microscopy
}

\author{
Akira Shibata ${ }^{1,4, *}$, Yoichi Goto ${ }^{1}$, Hiroaki Saito ${ }^{2}$, Tomohiko Kikuchi ${ }^{3}$, Tatuki Toda ${ }^{1}$, \\ Satoru Taguchi ${ }^{1}$ \\ ${ }^{1}$ Faculty of Engineering, Soka University, 1-236 Tangi-cho, Hachioji, Tokyo 192-8577, Japan \\ ${ }^{2}$ Tohoku National Fisheries Research Institute, Shinhama-cho 3-27-5, Shiogama 985-0001, Japan \\ ${ }^{3}$ Faculty of Education and Human Sciences, Yokohama National University, 792 Tokiwadai, Hodogaya, \\ Yokohama 240-8501, Japan \\ ${ }^{4}$ Present address: Department of Aquatic Bioscience, Graduate School of Agricultural and Life Sciences, \\ University of Tokyo, 1-1-1 Yayoi, Bunkyo-ku, Tokyo 113-8657, Japan
}

\begin{abstract}
SYBR Gold staining is used for enumerating bacteria and viruses in aquatic samples. However, its suitability for epifluorescence microscopy has not been sufficiently investigated. Thus we compared bacterial and viral counts using SYBR Gold and SYBR Green I stains. Variables for both bacterial and viral counts included season and ocean depths of sample collection and the period of sustained excitation under epifluorescence microscopy. We also examined the storage period and procedures for preservation of samples with formaldehyde for bacterial counts. Natural seawater samples were used for all experiments. Ratios of counts obtained with SYBR Gold to those with SYBR Green I staining were $0.99 \pm 0.09$ (mean $\pm \mathrm{SD}, \mathrm{n}=58$ ) for bacteria and $1.0 \pm 0.1(\mathrm{n}=38)$ for viruses, which indicated no significant differences between stains. In samples fixed with $0.74 \%$ formaldehyde that were stored at $4^{\circ} \mathrm{C}$, bacterial counts obtained with SYBR Gold staining decreased over time in parallel with those obtained with SYBR Green I staining. However, counts from fixed samples with both SYBR stains did not decrease significantly after $30 \mathrm{~d}$ when glass slides were prepared immediately and stored at $-20^{\circ} \mathrm{C}$, or when samples were flash-frozen in liquid nitrogen and stored at $-80^{\circ} \mathrm{C}$. Under sustained excitation, counts of bacteria and viruses stained with SYBR Gold decreased less than with SYBR Green I, suggesting greater persistence of the fluorescence signal with SYBR Gold. These results indicate the suitability of SYBR Gold staining for use in the determination of bacterial and viral abundance in natural seawater.
\end{abstract}

KEY WORDS: SYBR Green I · SYBR Gold · Bacteria · Virus · Enumeration · Epifluorescence microscopy

Resale or republication not permitted without written consent of the publisher

\section{INTRODUCTION}

Epifluorescence microscopy has been widely used for determining the abundance of bacteria and viruses, and still contributes to the clarification of the roles of these microbes in trophic dynamics and biogeochemical fluxes in the oceans (Azam et al. 1983, Suttle et al. 1990, Ducklow \& Carlson 1992, Weinbauer \& Suttle
1997, Ducklow 1999, Nagata et al. 2000, Hansell \& Ducklow 2003, Reinhtaler et al. 2005). With this technique, fluorochrome-stained microbes that are collected on filters are counted (Hobbie et al. 1977, Porter \& Feig 1980, Hara et al. 1991). Noble \& Fuhrman (1998) recommended concentrating the bacteria and viruses on $0.02 \mu \mathrm{m}$ pore-size Anodisc filters and staining them with SYBR Green I for counting. Because of its bright 
and stable fluorescence, SYBR Green I stain is now widely used in studies of aquatic microbial ecology that employ epifluorescence microscopy (Arrieta et al. 2004, Hewson et al. 2004, Schwalbach et al. 2004, Staroscik \& Smith 2004, Weinbauer et al. 2004, Winter et al. 2004) as well as flow cytometry (Marie et al. 1997, Marie et al. 1999, Brussaard 2004).

SYBR Gold (Invitrogen), a fluorescent dye, detects double- and single-stranded DNA and RNA and is more sensitive than SYBR Green I for staining these nucleic acids on gels (Tuma et al. 1999). In fact, staining cultured Escherichia coli cells (Weinbauer et al. 1998) and cyanophages (Chen et al. 2001) with SYBR Gold produces more intense fluorescence than SYBR Green I. Chen et al. (2001) noted that when viruses stained with SYBR Gold were exposed to sustained excitation, the fluorescence emitted lasted longer than that of viruses stained with SYBR Green I. Viral counts obtained with epifluorescence microscopy using SYBR Gold staining in river water samples $(n=10)$ were higher than those obtained using transmission electron microscopy (Chen et al. 2001), suggesting a methodological advantage of SYBR Gold staining. Although SYBR Gold staining has come into use in more recent investigations (Fischer et al. 2004, Williamson \& Paul 2004), the effect of fluorescence properties of SYBR Gold stain on estimates of bacterial abundance has not been well documented in comparison with SYBR Green I.

Investigating the suitability of SYBR Gold staining, only a few studies compared data on viral abundance obtained with SYBR Green I and SYBR Gold, and the results differed somewhat. Among samples of 8 different isolates and 1 natural assemblage of viruses, comparison of flow cytometry data revealed significantly higher counts of viruses stained with SYBR Green I than with SYBR Gold (Brussaard 2004). In contrast, the results of enumeration using epifluorescence microscopy were basically indistinguishable when viruses from a limited number of stored fresh- and seawater samples $(n=3)$ were stained with each of the 2 SYBR reagents (Wen et al. 2004). Thus, comparative data on viral counts are very sparse, particularly those on natural aquatic samples, and to our knowledge such comparisons have not been made for bacterial counts. Therefore, we compared bacterial and viral abundance data and the effect of several variables on the results to further elucidate the suitability and advantages of SYBR Gold staining for enumerating bacteria and viruses using epifluorescence microscopy.

Variables considered for both viral and bacterial counts included season and depths at which samples were collected from the ocean and the period of sustained excitation under epifluorescence microscopy. With regard to bacterial counts, we examined the stor- age period and procedures for the preservation of samples with formaldehyde. Viral counts during storage were not compared between the 2 stains because results of such comparison were reported by Wen et al. (2004). In addition, to obtain information on the optimization of the SYBR Gold technique, the pore size of the Anodisc filter suitable for concentrating bacteria and the type of anti-fade mounting material used in preparing the glass slides for both bacterial and viral counts were investigated with this stain. All experiments were made using natural seawater samples.

\section{MATERIALS AND METHODS}

Sample collection. Between April 2003 and May 2005, at a site $2 \mathrm{~km}$ off the Manazuru Peninsula in Sagami Bay, Japan $\left(35^{\circ} 09^{\prime} \mathrm{N}, 139^{\circ} 10^{\prime} \mathrm{E}\right)$, seawater samples were collected using Niskin bottles at depths between 0 and $100 \mathrm{~m}$. Disposable $2 \mathrm{ml}$ cryogenic vials or $50 \mathrm{ml}$ centrifuge tubes (Corning, Cat. No. 430659 or 430291, respectively) were washed with the sample seawater 3 times and then filled. Samples were fixed with formaldehyde at a final concentration of $0.74 \%$ immediately after collection. This fixative was filtered with $0.02 \mu \mathrm{m}$ pore-size Anodisc filters before use to prevent contamination of bacteria and viruses in this fixative. Those samples were subsequently treated with one of the following procedures: (1) storage in darkness at $4^{\circ} \mathrm{C}$ until analysis, (2) preparation of glass slides followed by storage at $-20^{\circ} \mathrm{C}$, or (3) flashfreezing in liquid nitrogen followed by storage at $-80^{\circ} \mathrm{C}$.

Counts of bacteria and viruses. Bacteria and viruses from samples stained with either SYBR Green I or SYBR Gold were counted using the SYBR Green I protocol of Noble \& Fuhrman (1998) with slight modifications. Seawater samples (1 to $3 \mathrm{ml}$ ) were filtered through an Anodisc filter, $0.02 \mu \mathrm{m}$ pore-size (Whatman), backed by a $0.45 \mu \mathrm{m}$ pore-size cellulose membrane filter (Millipore). The Anodisc filter was dried, placed in a petri dish on a drop of SYBR Green I or SYBR Gold stain (final dilution $2.5 \times 10^{-3}$ ) with the side of the filter that retained the bacteria and viruses facing upwards, and kept in the dark for $15 \mathrm{~min}$. The original SYBR Green I and SYBR Gold reagents have an OD494 (optical density) of 1.2 and 1.0, respectively, when diluted 400-fold with sterilized distilled water. The stained Anodisc filter was completely dried and mounted on a glass slide with a drop of anti-fade mounting reagent. The reagent used was either $50 \%$ glycerol, $50 \%$ phosphate buffered saline with $0.1 \%$ $p$-phenylenediamine (GPP), or a commercially available anti-fade mounting reagent, SlowFade Light (Invitrogen). 
In addition to using the SYBR reagents, bacterial counts for the storage experiment were also performed using the original 4',6'-diamidino-2-phenylindole (DAPI) staining protocol (Porter \& Feig 1980) in which seawater was stained with DAPI (final concentration $1.0 \mu \mathrm{g} \mathrm{ml}^{-1}$ ) for $20 \mathrm{~min}$ and then filtered onto a $0.2 \mu \mathrm{m}$ pore-size polycarbonate Nuclepore filter (Whatman).

An Axioskop 2 plus epifluorescence microscope equipped with an HBO 100 mercury lamp (Carl Zeiss) was used for counting bacteria and viruses on filters mounted on glass slides and covered with a coverslip. Blue (excitation from 465 to $505 \mathrm{~nm}, 510 \mathrm{~nm}$ cutoff; emission from 515 to $565 \mathrm{~nm}$ ) and UV (excitation from 353 to $377 \mathrm{~nm}, 395 \mathrm{~nm}$ cutoff; emission from > $397 \mathrm{~nm}$ ) optical filter sets were used when counts were done under microscopy using the SYBR and DAPI methods, respectively. A minimum of 20 randomly selected fields were examined, producing a count of at least 400 bacterial cells or viral particles; each count in a microscopic field was done within 10 to $15 \mathrm{~s}$ of commencement of excitation.

Comparisons of variables affecting bacterial and viral counts. For comparisons of the 2 stains for samples collected at different ocean depths and seasons, bacterial counts in seawater collected during various periods from April to November 2003 and at depths between 0 and $100 \mathrm{~m}$ were compared $(\mathrm{n}=26)$. Samples were fixed and kept at $4^{\circ} \mathrm{C}$ for preparation of glass slides with SlowFade Light within 2 d, after which counts were done immediately. Samples collected at the same depths from November 2004 to May 2005 (bacterial counts $n=32$; viral counts $n=38$ ) were also used for comparisons of the 2 stains. These samples were fixed and kept at $4^{\circ} \mathrm{C}$ for $30 \mathrm{~min}$, slides were prepared with GPP, and then the counts were done immediately.

For a time course investigation of the decrease in bacterial counts during storage, samples collected at a depth of $10 \mathrm{~m}$ in November and December of 2004 and January 2005 ( $\mathrm{n}=3$ ) were placed with several polypropylene tubes (volume, $50 \mathrm{ml}$ ), fixed in $0.74 \%$ formaldehyde, and stored at $4{ }^{\circ} \mathrm{C}$. Sub-samples were then taken at each time point from the samples that had been stored in tubes, and bacteria were stained with either the SYBR Green I, SYBR Gold, or the original protocol for the DAPI method (Porter \& Feig 1980). Quadruplicate slides were prepared for each stain type and counts were done immediately. Approximately 15 to $30 \mathrm{ml}$ of seawater sample was used from 1 tube for washing tips and for filtering samples in the process of preparing glass slides $(\mathrm{n}=$ 12 for 3 methods) at each time point. The residue of sample from that tube was not further used. The samples stored in each of the other tubes were used at each subsequent time point.
Comparisons of the decrease in bacterial counts between the 2 stains after storage of formaldehydefixed samples were made using the following 2 methods: glass slides prepared immediately for storage at $-20^{\circ} \mathrm{C}$, and flash-freezing of samples in liquid nitrogen for storage at $-80^{\circ} \mathrm{C}$. Samples collected from the same depth in May, June, and August 2005 (n = 3) were placed in polypropylene tubes (volume, 2 or $50 \mathrm{ml}$ ) and fixed with formaldehyde for $30 \mathrm{~min}$. Glass slides for each storage method were prepared in quadruplicate and bacteria were counted after $30 \mathrm{~d}$. When samples were flash-frozen in liquid nitrogen for storage at $-80^{\circ} \mathrm{C}$, tubes with a volume of $2 \mathrm{ml}$ were used for storing the sample to prevent breakage during this processing. The tips were washed as described above and 1 to $2 \mathrm{ml}$ of samples in another tube was used for filtering the sample at either the initial time point or $30 \mathrm{~d}$ later. The residue of the sample in the tube used at the initial time point was not further used. The sample that was stored at $-80^{\circ} \mathrm{C}$ in another tube was used at a later point in time.

To investigate the duration of bacterial and viral florescence while counts were being made under sustained excitation, a seawater sample collected at a depth of 10 m during December 2004 was used. Bacteria and viruses from this sample were treated with the 2 SYBR stains, GPP was applied to the slide and counts were made in 10 randomly selected microscopic fields.

Optimization of SYBR Gold staining. To obtain information on the optimization of the SYBR Gold staining technique, we investigated the impact of Anodisc filter pore size and the type of anti-fade mounting material used in preparing the glass slides. Bacteria in seawater samples collected at depths between 0 and $100 \mathrm{~m}$ from November 2004 to January 2005 ( $\mathrm{n}=21$ ) were concentrated on 0.2 and $0.02 \mu \mathrm{m}$ filters, stained with SYBR Gold, and then enumerated.

For comparison of counts between slides prepared with the 2 anti-fade reagents, we used a sample collected at a depth of $10 \mathrm{~m}$ in January 2005 to perform bacterial or viral counts from stained slides that were prepared with either the anti-fade mounting reagent GPP or SlowFade Light. Counts were compared according to the duration of sustained excitation. Bacteria and viruses were counted from 10 randomly selected microscopic fields.

Statistical analysis. Statistical analysis for a time course investigation of the decrease in bacterial counts in samples fixed with $0.74 \%$ formaldehyde during storage at $4{ }^{\circ} \mathrm{C}$ was performed using a 1-way ANOVA for the counts obtained with each method at each time point, followed by Dunnett's multiple comparison test. Two-tailed Student's $t$-tests were also performed to investigate the decrease in bacterial counts after storage with the following 2 methods: glass slides pre- 


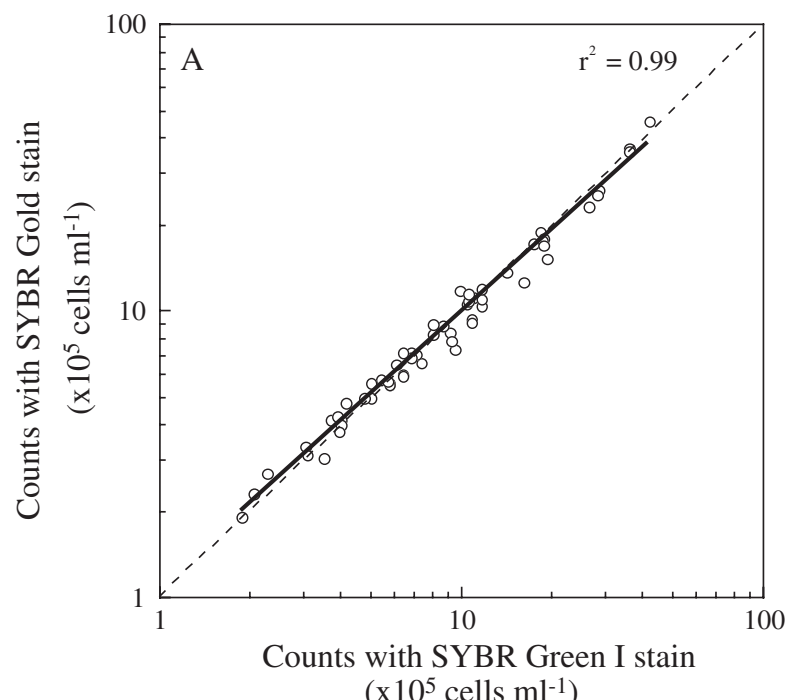

$\left(\mathrm{x} 10^{5}\right.$ cells $\left.\mathrm{ml}^{-1}\right)$

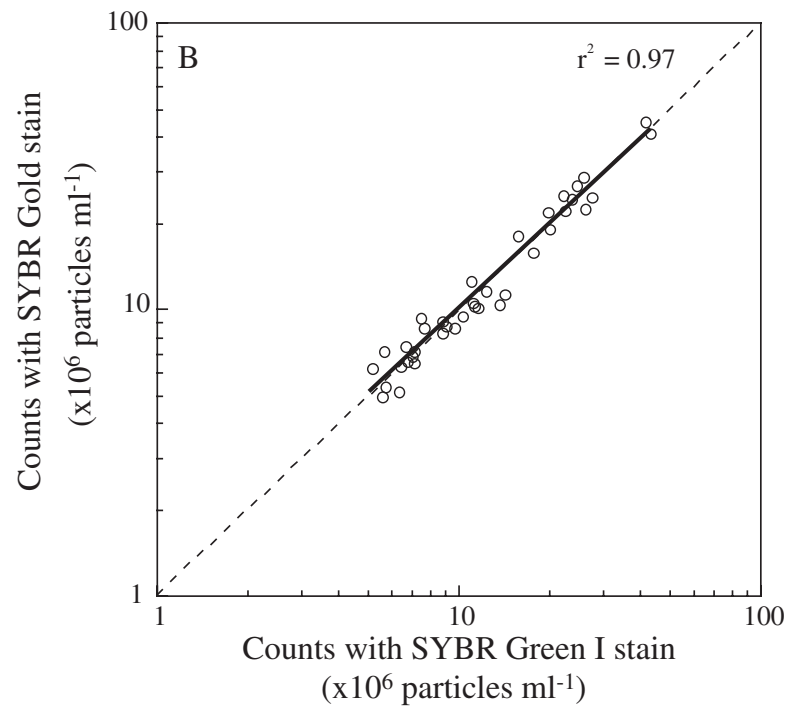

Fig. 1. Relationship between counts of (A) bacteria and (B) viruses stained with either SYBR Green I or SYBR Gold. Solid line represents regression equation derived from all samples used for the comparison. Dashed line represents assumption that counts from the 2 SYBR staining reagents are identical

pared immediately for storage at $-20^{\circ} \mathrm{C}$, and flashfreezing of samples in liquid nitrogen for storage at $-80^{\circ} \mathrm{C}$. Values of $\mathrm{p}<0.05$ were considered statistically different.

\section{RESULTS}

\section{Bacterial and viral counts from natural samples}

Counts using epifluorescence microscopy of bacteria stained with SYBR Gold were significantly correlated with those prepared with SYBR Green I stain $\left(\mathrm{r}^{2}=0.99\right.$, $\mathrm{n}=58, \mathrm{p}<0.001)$ (Fig. 1), as were viral counts $\left(\mathrm{r}^{2}=0.97\right.$, $\mathrm{n}=38, \mathrm{p}<0.001)$. The SYBR Gold:SYBR Green I ratios of bacterial and viral counts, $0.99 \pm 0.09$ (mean \pm SD) and $1.0 \pm 0.1$, respectively, show that the counts of each microbe using the 2 SYBR reagents were not significantly different. In addition, the ratio of bacterial counts using SYBR Gold staining was $1.0 \pm 0.1(\mathrm{n}=21)$ when comparing 0.2 with $0.02 \mu \mathrm{m}$ pore-size Anodisc filters, indicating that pore size made no significant difference to results of bacterial counts.

\section{Storage of samples fixed with formaldehyde}

In the samples fixed with formaldehyde that were stored at $4^{\circ} \mathrm{C}$, the relative bacterial counts obtained

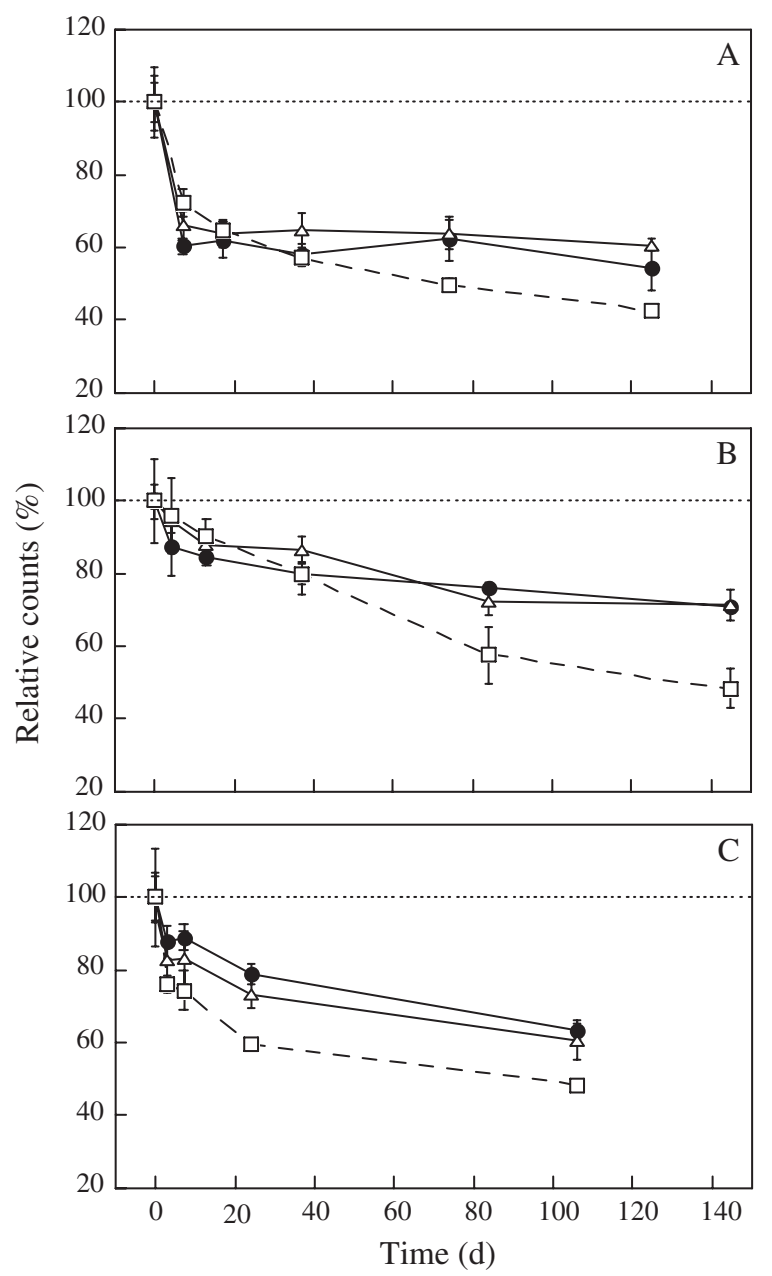

Fig 2. Changes in bacterial counts obtained with SYBR Green I (๑), SYBR Gold $(\Delta)$, and DAPI staining methods ( $\square$ ) in samples fixed with formaldehyde during storage at $4^{\circ} \mathrm{C}$. Samples were collected in (A) November and (B) December 2004 and (C) January 2005 at a coastal site. Dotted line represents assumption that counts of stored samples are identical to initial counts at time zero. Error bars $= \pm \operatorname{SD}(n=4)$ 


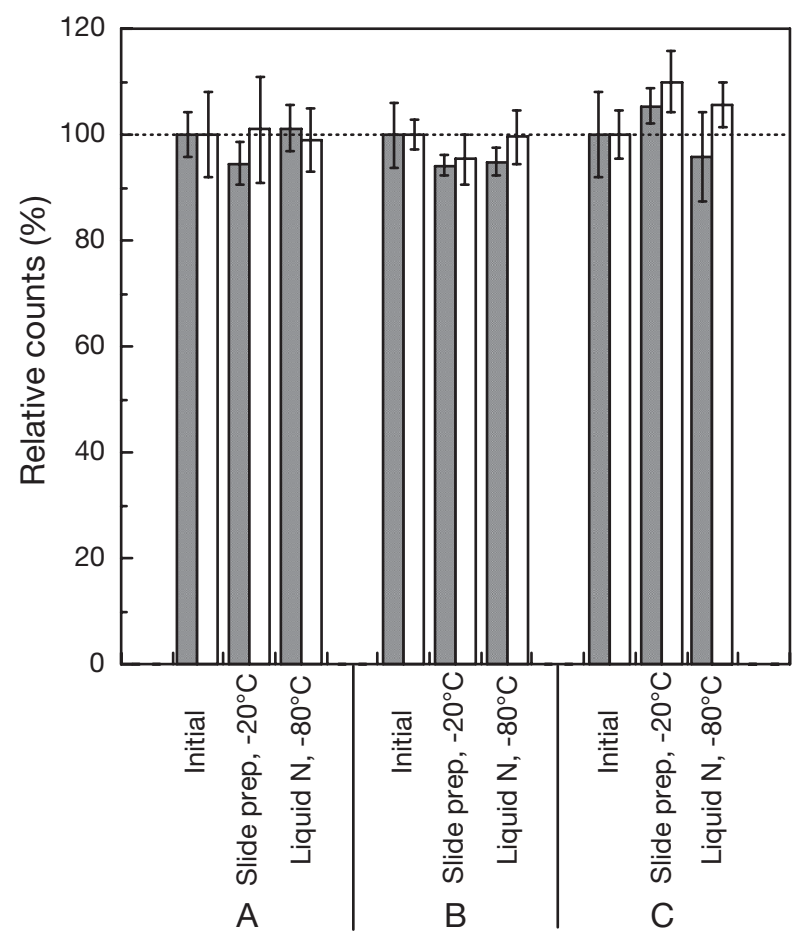

Fig. 3. Changes from initial bacterial counts with SYBR Green I (gray bars) and SYBR Gold (white bars) staining obtained from samples fixed with formaldehyde and stored for $30 \mathrm{~d}$ under 2 conditions: glass slides prepared immediately and stored at $-20^{\circ} \mathrm{C}$; samples flash-frozen in liquid nitrogen and stored at $-80^{\circ} \mathrm{C}$. Samples were collected in (A) May, (B) June, and (C) August 2005 at a coastal site. Dotted line represents assumption that counts of the stored samples are identical to initial counts at time zero. Error bars $= \pm \operatorname{SD}(n=4)$

from SYBR Gold staining decreased in parallel with those from SYBR Green I staining (Fig. 2). There were no significant differences in the relative counts between SYBR Green I and SYBR Gold staining at any time point in any of the storage experiments. In contrast, the relative counts obtained from the DAPI method were significantly lower than those from SYBR Green I staining from Day 74, 84, and 7 onward in the fixed samples collected in November and December 2004 and January 2005, respectively (Dunnett's multiple comparison test, $\mathrm{p}<0.05$ ). The difference became more pronounced with the length of the storage period.

During storage under this condition, bacterial counts using the 3 methods decreased quickly in the early part of the storage period and then more slowly. The fastest decline was observed between time zero and the second time point; counts by the 3 methods dropped, on average, by $34 \%$ within $7 \mathrm{~d}, 7.3 \%$ within $4 \mathrm{~d}$, and $18 \%$ within $3 \mathrm{~d}$ in samples collected in November and December 2004 and January 2005, respectively. The rates of decline for these periods were between 0.018 and $0.059 \mathrm{~d}^{-1}$. The slowest decline was observed between the penultimate and last time points; the SYBR counts decreased, on average, by $5.4 \%$ within $51 \mathrm{~d}, 3.2 \%$ within $61 \mathrm{~d}$, and $14 \%$ within $82 \mathrm{~d}$ in samples collected in November and December 2004 and January 2005, respectively. Between these same time points (penultimate and last time points), the DAPI counts decreased by $7.2 \%$ within $51 \mathrm{~d}, 9.1 \%$ within $61 \mathrm{~d}$, and $11 \%$ within $82 \mathrm{~d}$ in samples collected in November and December 2004 and January 2005, respectively. The rates of decline for these periods were between 0.00052 and $0.0017 \mathrm{~d}^{-1}$ and 0.0014 and $0.0015 \mathrm{~d}^{-1}$ for the SYBR and DAPI counts, respectively.

In samples fixed with formaldehyde and stored for $30 \mathrm{~d}$, bacterial counts obtained with either SYBR Green I or SYBR Gold staining did not decrease significantly compared with counts made at time zero (Fig. 3) when glass slides were prepared immediately for storage at $-20^{\circ} \mathrm{C}$ or when samples were flash-frozen in liquid nitrogen for storage at $-80^{\circ} \mathrm{C}$.

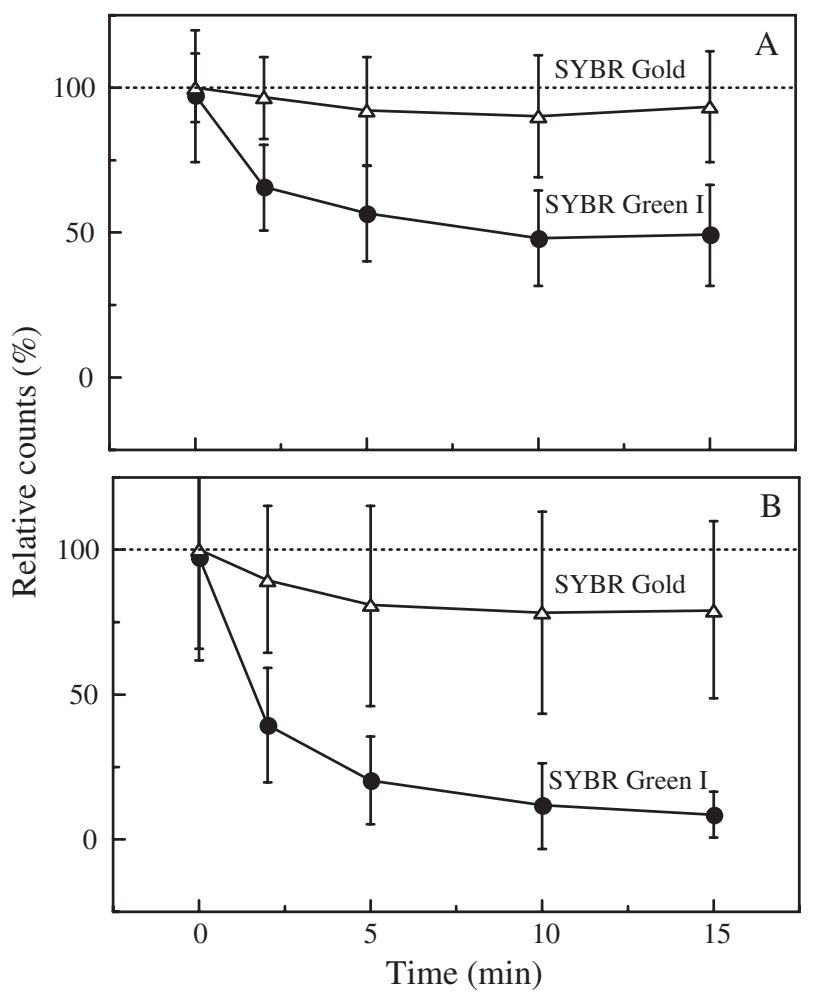

Fig. 4. Change under sustained excitation from initial counts of (A) bacteria and (B) viruses stained with SYBR Green I or SYBR Gold when glass slides were prepared with anti-fade mounting reagent $50 \%$ glycerol, $50 \%$ phosphate buffered saline with $0.1 \%$ p-phenylenediamine. Dotted line represents assumption that counts under excitation are identical to initial counts at time zero. Error bars $= \pm \operatorname{SD}(\mathrm{n}=10)$ 


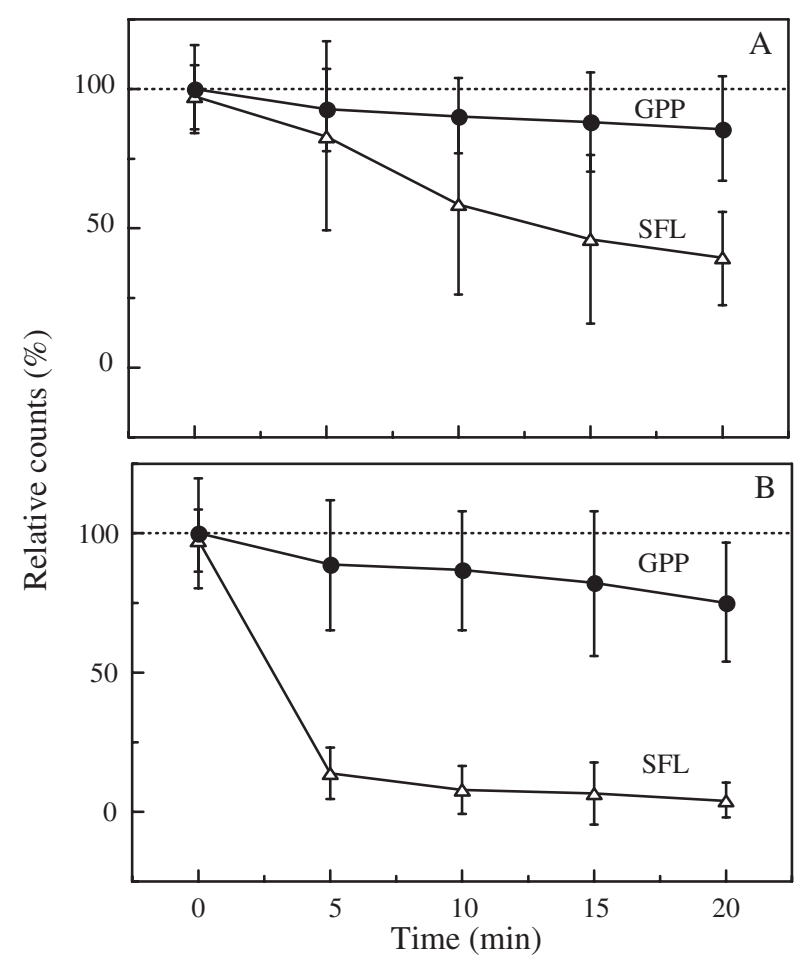

Fig. 5. Change under sustained excitation from initial counts of (A) bacteria and (B) viruses stained with SYBR Gold on slides prepared with anti-fade mounting reagent GPP or SlowFade Light (SFL). Dotted line represents assumption that counts under excitation are identical to initial counts at time zero. Error bars $= \pm \mathrm{SD}(\mathrm{n}=10)$

\section{Bacterial and viral counts according to time of excitation}

Under sustained blue excitation, counts of bacteria and viruses stained with SYBR Green I following treatment of slides with GPP decreased to 49 and $9 \%$, respectively, of their initial values within $15 \mathrm{~min}$, whereas those stained with SYBR Gold decreased to 93 and $79 \%$, respectively (Fig. 4). Thus, these results indicate that decreases upon excitation occurred more quickly with SYBR Green I stain than with SYBR Gold.

A comparison was made using slides that were prepared with 2 types of anti-fade mounting material. Results of counts made under sustained excitation by bacteria and viruses stained with SYBR Gold revealed the influence of anti-fade mounting materials (Fig. 5). When slides were prepared with GPP, counts of bacteria and viruses stained with SYBR Gold decreased to 88 and $82 \%$, respectively, of their initial values after $15 \mathrm{~min}$. In contrast, with SlowFade Light, counts of bacteria and viruses stained with SYBR Gold decreased to 46 and $7 \%$, respectively. These results indicate that under sustained excitation the use of GPP resulted in greater stability of counts than SlowFade Light.

\section{DISCUSSION}

\section{Reliability of bacterial and viral counts}

Our comparisons showed that counts of bacteria or viruses stained with SYBR Gold did not differ significantly from those stained with SYBR Green I. This result of viral counts was consistent with those of Wen et al. (2004), who reported that epifluorescence counts of viruses stained with the 2 SYBR reagents were statistically indistinguishable in both stored fresh and seawater samples. The equivalence of results for the 2 SYBR stains is also supported by the similar binding specificities of the fluorochromes for double-stranded DNA, single-stranded DNA, and RNA (Invitrogen; Tuma et al. 1999). Thus, we demonstrated the reliability of bacterial and viral counts using SYBR Gold staining with epifluorescence microscopy.

That there was no significant difference between counts of bacteria concentrated on 0.2 and $0.02 \mu \mathrm{m}$ pore-size Anodisc filters demonstrated the suitability of the filter with larger pores for concentrating bacteria from aquatic samples. The filtration rate of such filters is approximately 3 -fold faster than filters with $0.02 \mu \mathrm{m}$ pores (data not shown), making possible the speedy filtration of samples for bacterial counts.

Our finding of statistically indistinguishable counts of viruses stained with SYBR Green I and with SYBR Gold differs from recent comparable data on viruses counted by flow cytometry (Brussaard 2004), which show significantly higher counts with SYBR Green I staining than with SYBR Gold staining. However, it would be inappropriate to make a simple comparison between the 2 sets of results, as counting procedures differed between the 2 studies. Differences included pre-treatment (not done in our study), the dilution level of the SYBR reagents (1:20000 [Brussaard 2004] vs. 1:400 [our study]), counting instrument used (flow cytometry vs. epifluorescence microscopy), and the samples tested (mainly isolates vs. natural assemblages). Therefore, in our study, it should be noted that the reliability of both viral and bacterial counts obtained with SYBR Gold staining was shown using epifluorescence microscopic examination of natural seawater samples.

\section{Decrease in bacterial counts in fixed samples during storage}

The results from our comparison demonstrated that bacterial counts obtained with SYBR Gold and SYBR Green I stains did not differ significantly in samples fixed with formaldehyde that were stored at $4{ }^{\circ} \mathrm{C}$; however, these counts decreased with storage time. These 
decreases were consistent with the results of previous studies, which reported that bacterial counts obtained using the original DAPI or Acridine Orange (AO) methods decreased with the length of the storage period in aldehyde-fixed samples, and that counts decreased sharply by 7 to $75 \%$ within 40 d (Turley \& Hughes 1992), 26 to $31 \%$ within 15 d (Turley \& Hughes 1994), 24 to $50 \%$ within 7 to 29 d (Gundersen et al. 1996), and $>30 \%$ within $40 \mathrm{~d}$ (Vosjan \& Noort 1998). The sharp decrease (by 7.3 to $31 \%$ within 3 to 7 d) observed in the early storage period of our experiment appears to be slightly higher than those decline levels reported previously. Our observations were made for a shorter time span ( 3 to $7 \mathrm{~d}$ ) than in other studies ( 7 to $40 \mathrm{~d}$ ); however, our results can be considered to be in line with those of previous studies because the rate of decrease declined with increases in the storage period even in the early storage period.

With the original DAPI staining protocol, there was a more rapid decrease in counts in relation to storage time than with the SYBR methods, and, thus, relative differences became more pronounced between the DAPI and SYBR counts with increasing storage time. These results suggest an advantage of SYBR staining over DAPI methods for counting bacteria. However, storage of formaldehyde-fixed samples at $4^{\circ} \mathrm{C}$ could result in an underestimation of bacterial abundance in natural environments because counts decrease over time regardless of the counting method used (Turley \& Hughes 1992, Gundersen et al. 1996), as was also suggested by Wen et al. (2004) when counting viruses.

One important finding of our study is that bacterial counts from fixed samples stained with SYBR Green I or SYBR Gold did not decrease significantly during storage when glass slides were prepared immediately for storage at $-20^{\circ} \mathrm{C}$, or when samples were flashfrozen in liquid nitrogen for storage at $-80^{\circ} \mathrm{C}$. Samples so treated could be stored without a decrease in counts for at least $30 \mathrm{~d}$, with the potential for a longer storage duration. The result in the former storage condition is consistent with a previous result obtained from glutaraldehyde-fixed samples, which showed that there was no significant loss of counts from glass slides stored under a similar condition $(n=58)$ when these recounts had been completed within $70 \mathrm{~d}$ by the AO method (Turley \& Hughes 1992). However, the specific temperature for storage and the time period for each recount of each sample were not shown clearly in this previous study. Our results systematically confirmed the effectiveness of this procedure, i.e. preparing glass slides immediately using formaldehyde-fixed samples and storing them at $-20^{\circ} \mathrm{C}$.

In addition, we demonstrated the effectiveness of another procedure for storing samples using flashfreezing in liquid nitrogen. That procedure is very use- ful when there is not sufficient time to process a lot of samples such as during a scientific research cruise. These storage procedures would resolve the problem of underestimation of bacterial abundance due to a decrease in bacterial counts in fixed samples. It is also notable that decreases in viral counts could be prevented by similar storage procedures prior to enumeration with either epifluorescence microscopy (Wen et al. 2004) or flow cytometry (Brussaard 2004).

\section{Stability of bacterial and viral counts under sustained excitation}

Bacterial and viral counts obtained with SYBR Gold stain were more stable than those with SYBR Green I stain regardless of the duration of excitation. The fluorescence-quenching characteristic of the 2 SYBR stains is consistent with the report by Chen et al. (2001), who noted that fluorescence emitted from viruses with SYBR Gold stain lasted longer than that with SYBR Green I under sustained excitation. To our knowledge, however, there have been no experimental data on comparisons of the influence of the stability of fluorescence emitted from bacteria and viruses with the 2 SYBR stains on their counts by epifluorescence microscopy. Our results strongly suggest that bacterial and viral counts using SYBR Gold staining remain stable for longer than that with SYBR Green I staining under sustained excitation. This fluorescence property of SYBR Gold facilitates clear microscopic visualization regardless of excitation time.

Anti-fade mounting materials influenced the fading properties of bacteria and viruses stained with the SYBR reagents under sustained excitation, even though bacterial and viral counts with SYBR Gold staining were statistically indistinguishable immediately after excitation regardless of the mounting material used (data not shown). Our results showed that bacterial and viral counts using SYBR Gold staining remained stable for longer with GPP than with SlowFade Light. Noble \& Fuhrman (1998) stated that the use of GPP minimized the fading of SYBR Green I fluorescence. Similarly, our results strongly suggest that GPP is also the more effective anti-fade material to prevent fading of SYBR Gold fluorescence.

\section{CONCLUSIONS}

Bacterial and viral counts obtained with SYBR Gold stain were statistically indistinguishable from counts with SYBR Green I stain. However, counts obtained with SYBR Gold were stable for longer than with SYBR Green I stain under sustained blue excitation. This pro- 
longed endurance of fluorescence would assist in microscopic observation and enumeration of microbes. If counting is not done immediately after fixation of samples with formaldehyde, the best procedure for preventing a decrease in counts during storage is to prepare the slides immediately and store them at $-20^{\circ} \mathrm{C}$, or to flash-freeze samples with liquid nitrogen and store them at $-80^{\circ} \mathrm{C}$. Similar procedures have already been recommended for storing samples for viral counts (Brussaard 2004, Wen et al. 2004). In studies to optimize the methodology with SYBR Gold, we found that filtration through a $0.2 \mu \mathrm{m}$ pore-size Anodisc filter is applicable for bacterial counts and that GPP is an effective material when preparing glass slides to prevent the fading of SYBR Gold fluorescence. From these results, we consider that SYBR Gold staining processed according to these procedures is suitable for determining aquatic bacterial and viral abundance with epifluorescence microscopy and that it offers the advantage of prolonged endurance of fluorescence.

Acknowledgements. We thank students from the oceanographic laboratories, Soka University and Yokohama National University for their kind help in collecting samples. We are grateful to Grieg Steward and Ian Hewson for their valuable comments on an earlier version of this manuscript. Comments and suggestions from 3 anonymous reviewers were very helpful in improving the manuscript. This study was partially supported by Grant-in-Aid for Young Scientists (\#14760126), Scientific Research (\#14103001), and UniversityIndustry Joint Research Project (2004-2008) from the Ministry of Education, Science, Sports and Culture, Japan.

\section{LITERATURE CITED}

Arrieta JM, Weinbauer MG, Lute C, Herndl GJ (2004) Response of bacterioplankton to iron fertilization in the Southern Ocean. Limnol Oceanogr 49:799-808

Azam F, Fenchel T, Field JG, Gray JS, Meyer-Reil LA, Thingstad $F$ (1983) The ecological role of water column microbes in the sea. Mar Ecol Prog Ser 10:257-263

Brussaard CPD (2004) Optimization of procedures for counting viruses by flow cytometry. Appl Environ Microbiol 70: 1506-1513

Chen F, Lu J, Binder B, Liu Y, Hodson RE (2001) Application of digital image analysis and flow cytometry to enumerate marine viruses stained with SYBR Gold. Appl Environ Microbiol 67:539-545

Ducklow HW (1999) The bacterial component of the oceanic euphotic zone. FEMS Microbiol Ecol 30:1-10

Ducklow HW, Carlson CA (1992) Oceanic bacterial production. Adv Microbial Ecol 12:113-181

Fischer UR, Weisz W, Wieltschnig C, Kirschner AKT, Velimirov B (2004) Benthic and pelagic viral decay experiments: a model-based analysis and its application. Appl Environ Microbiol 70:6706-6713

Gundersen K, Bratbak G, Heldal M (1996) Factors influencing the loss of bacteria in preserved seawater samples. Mar Ecol Prog Ser 137:305-310
Hansell DA, Ducklow HW (2003) Bacterioplankton distribution and production in the bathypelagic ocean: directly coupled to particulate organic carbon export? Limnol Oceanogr 48:150-156

Hara S, Terauchi K, Koike I (1991) Abundance of viruses in marine waters: assessment by epifluorescence and transmission electron microscopy. Appl Environ Microbiol 57: 2731-2734

Hewson I, Govil SR, Capone DG, Carpenter EJ, Fuhrman JA (2004) Evidence of Trichodesmium viral lysis and potential significance for biogeochemical cycling in the oligotrophic ocean. Aquat Microb Ecol 36:1-8

Hobbie JE, Daley CA, Jasper S (1977) Use of Nuclepore filters for counting bacteria by fluorescence microscopy. Appl Environ Microbiol 33:1225-1228

Marie D, Partensky F, Jacquet S, Vaulot D (1997) Enumeration and cell cycles analysis of natural populations of marine picoplankton by flow cytometry. Appl Envrion Microbiol 63:186-193

Marie D, Brussaard CPD, Thyrhanug R, Bratbak G, Vaulot D (1999) Enumeration of marine viruses in culture and natural samples by flow cytometry. Appl Envrion Microbiol 65:45-52

Nagata T, Fukuda H, Fukuda R, Koike I (2000) Bacterioplankton distribution and production in deep waters: largescale geographic variations and possible coupling with sinking particle fluxes. Limnol Oceanogr 45:426-435

Noble RT, Fuhrman JA (1998) Use of SYBR Green I for rapid epifluorescence counts of marine viruses and bacteria. Aquat Microb Ecol 14:113-118

Porter KG, Feig YS (1980) The use of DAPI for identifying and counting aquatic microflora. Limnol Oceanogr 25:943-948

Reinthaler T, Winter C, Herndl GJ (2005) Relationship between bacterioplankton richness, respiration, and production in the Southern North Sea. Appl Envrion Microbiol 71:2260-2266

Schwalbach MS, Hewson I, Fuhrman JA (2004) Viral effects on bacterial community composition marine plankton microcosms. Aquat Microb Ecol 34:117-127

Staroscik AM, Smith DC (2004) Seasonal patterns in bacterioplankton abundance and production in Narragansett Bay, Rhode Island, US. Aquat Microb Ecol 35:275-282

Suttle CA, Chan AM, Cottrell MT (1990) Infection of phytoplankton by viruses and reduction of primary productivity. Nature 347:467-469

Tuma RS, Beaudet MP, Jim X, Jones LJ, Cheung C, Yue SV, Singer L (1999) Characterization of SYBR Gold nucleic acid gel stain: a dye optimized for use with 300-nm ultraviolet transilluminators. Anal Biochem 268:278-288

Turley CM, Hughes DJ (1992) Effect of storage on direct estimates of bacterial numbers of preserved seawater samples. Deep-Sea Res 39:375-394

Turley CM, Hughes DJ (1994) The effect of storage temperature on the enumeration of epifluorescence-detectable bacterial cells in preserved sea-water samples. J Mar Biol Assoc UK 74:259-262

Vosjan JH, van Noort GJ (1998) Enumerating nucleoid-visible marine bacterioplankton: bacterial abundance determined after storage of formalin fixed samples agrees with isopropanol rinsing method. Aquat Microb Ecol 14: 149-154

Weinbauer MG, Suttle CA (1997) Comparison of epifluorescence and trasmission electron microscopy for counting viruses in natural marne waters. Aquat Microb Ecol 13: $225-232$

Weinbauer MG, Beckmann C, Höfle MG (1998) Utility of green fluorescent nucleic acid dyes and aluminum oxide 
membrane filter for rapid epifluorescence enumeration of soil and sediment bacteria. Appl Envrion Microbiol 64: 5000-5003

Weinbauer MG, Brettar I, Höfle MG (2004) Lysogeny and virus-induced mortality of bacterioplankton in surface, deep, and anoxic marine waters. Limnol Oceanogr 48: $1457-1465$

Wen K, Ortmann AC, Suttle CA (2004) Accurate estimation of

Editorial responsibility: Jed Fuhrman,

Los Angeles, California, USA viral abundance by epifluorescence microscopy. Appl Envrion Microbiol 70:3862-3867

Williamson SJ, Paul JH (2004) Nutrient stimulation of lytic phage production in bacterial populations of the Gulf of Mexico. Aquat Microb Ecol 36:9-17

Winter C, Herndl GJ, Weinbauer MG (2004) Dial cycles in viral infection of bacterioplankton in the North Sea. Aquat Microb Ecol 35:207-216

Submitted: September 9, 2004; Accepted: March 20, 2006 Proofs received from author(s): June 21, 2006 